\title{
Obtenção da estética do sorriso através de laminados cerâmicos e coroas metal free: relato de caso
}

Rafaella Rodrigues GOMES'; Gustavo Moreira de ALMEIDA²; Kécia Teles Reis da Silva ALMEIDA'; Jenival Correia de ALMEIDA JÚNIOR ${ }^{4}$

\author{
1 - Mestra em Clínica Odontológica pela Universidade Federal de Uberlândia (UFU). Especialista em Prótese dentária pela \\ Faculdade Faipe - Coa \\ 2 - Doutor em Ciências da Saúde pela Universidade de Brasília (UnB). Professor Coordenador do Curso de Especialização em \\ Endodontia da Faculdade Faipe - Coa. \\ 3 - Especialista em Prótese Dentária pela Faculdade Faipe - Coa. \\ 4 - Mestre em Odontologia pelo Centro de Pesquisas Odontológicas São Leopoldo Mandic. Professor Coordenador do Curso de \\ Especialização em Prótese Dentária da Faculdade Faipe - Coa.
}

\section{Resumo}

Objetivo: Este relato de caso objetivou descrever o tratamento estético dos dentes anteriores, destacando as etapas em reabilitação oral, utilizando coroas e laminados de dissilicato de lítio. Material e Método: Após os procedimentos preliminares e de diagnóstico como a obtenção dos modelos de estudo, enceramento, e mock-up, foram realizados os preparos, seguidos de moldagem com silicone de adição, e as coroas e laminados foram confeccionadas e cimentadas com cimento resinoso. Resultados: Como um resultado disso, percebemos que a estética não deve somente devolver a forma e função dos elementos dentários, mas restabelecer um novo sorriso ao paciente, tendo a preocupação de preservar os tecidos dentários e manter a saúde do tecido periodontal. Conclusão: Após o relato deste caso clínico, percebemos que é possível reestabelecer a estética e função em pacientes insatisfeitos com seu sorriso, através da reabilitação com cerâmicas.

PALAVRAS-CHAVE: Estética dentária; Cerâmica; Facetas dentárias.

AUTOR PARA CORRESPONDÊNCIA

Prof. Me. Jenival Almeida Jr.

Centro de Odontologia Avançada, ABO de llhéus

Praça Rui Barbosa, 185 - Centro, Ilhéus - BA, Cep:45653-340

E-mail: drjenival1@hotmail.com 


\section{Introdução}

A crescente busca pela estética têm sido um dos principais motivos pelo quais os pacientes têm procurado tratamento em consultórios médicos e odontológicos, uma vez que um belo sorriso e estética facial harmônica contribuem para o bem-estar de qualquer paciente ${ }^{1}$. A estética do sorriso está relacionada à cor, forma, textura e alinhamento dos dentes anteriores, bem como às partes moles intraorais, lábios e estética facial. Um objetivo importante de um tratamento estético é que o resultado final seja o mais próximo possível das expectativas do paciente ${ }^{2}$.

A estética na odontologia vem se desenvolvendo amplamente com indicações de novas técnicas associadas ao emprego de materiais mais resistentes, mas que devolvem as características estéticas das estruturas dentais perdidas o que permite realizar transformações de sorriso com o mínimo possível de desgaste às estruturas dentais ${ }^{3}$.

Os laminados cerâmicos, quando confeccionadas em sua correta indicação e com um preciso protocolo clínico, possuem grande longevidade ${ }^{4}$. A composição química e a microestrutural dos materiais cerâmicos foram modificadas ao longo do tempo a fim de aumentar suas qualidades mecânicas e estéticas ${ }^{5,6}$. Os cristais de reforço inseridos nas cerâmicas como o dissilicato de lítio permitiram a produção de revestimentos cerâmicos mais finos, altamente estéticos e mais resistentes ao desgaste7.

A odontologia digital avançou rapidamente ao longo das últimas décadas. Os projetos auxiliados por computador como câmeras intraorais, CAD/CAM e impressoras 3D permitem fabricar vários tipos de restaurações usando materiais diferentes com maior previsibilidade do resultado final ${ }^{8}$. Essas tecnologias apresentam vantagens como melhor reprodutibilidade e precisão dimensional, melhor adaptação marginal da peça, facilidade de reprodução da oclusão e menor tempo de confecção?. 
O sucesso da técnica da restauração minimamente invasiva envolve a grande atenção aos detalhes dos procedimentos, como o correto planejamento do caso com uma avaliação criteriosa das indicações e contraindicações, preparo conservador dos dentes, seleção adequada de cerâmica, materiais e métodos de cimentação, acabamento e polimento adequado e manutenção continuada das restaurações ${ }^{10}$.

Em função de melhorar a estética comprometida pelas coroas insatisfatórias e os dentes com diferentes formas e alinhamento. Relata-se um caso clínico indicado para reabilitação estética de dentes anteriores com coroas e facetas laminadas de cerâmica reforçada por dissilicato de lítio.

\section{Material e método}

Paciente de 29 anos de idade, do sexo feminino, procurou tratamento estético dental porque estava insatisfeita com seu sorriso. A paciente relatou que sofreu trauma dentário quando criança, e em seguida realizou o tratamento endodôntico nos dois incisivos centrais. Após idade adulta pela insatisfação com seu sorriso procurou outros profissionais que indicaram a exodontia, seguida de implante do dente 11, entretanto a paciente desejava uma abordagem mais conservadora. No exame intraoral percebemos nos incisivos centrais a presença de coroa, restauração extensa insatisfatória, pino metálico amplo e tratamento endodôntico amplo; e em toda arcada superior percebemos diastemas, desgaste incisal, alteração de cor, forma e tamanho (Figura 1).

Após exame clínico, radiográfico (Figura 2), fotográfico, confecção de modelos de estudo, e para o diagnóstico, foi realizado o enceramento. As condições periodontais, presença de cáries, interferências oclusais, estética e simetria facial foram avaliadas. Com base em nossa avaliação, foi proposta uma abordagem de tratamento conservador, através de confecção de pino de fibra de vidro e coroa de dissilicato de lítio nos dois incisivos centrais e laminados cerâmico de dissilicato de lítio nos incisivos 


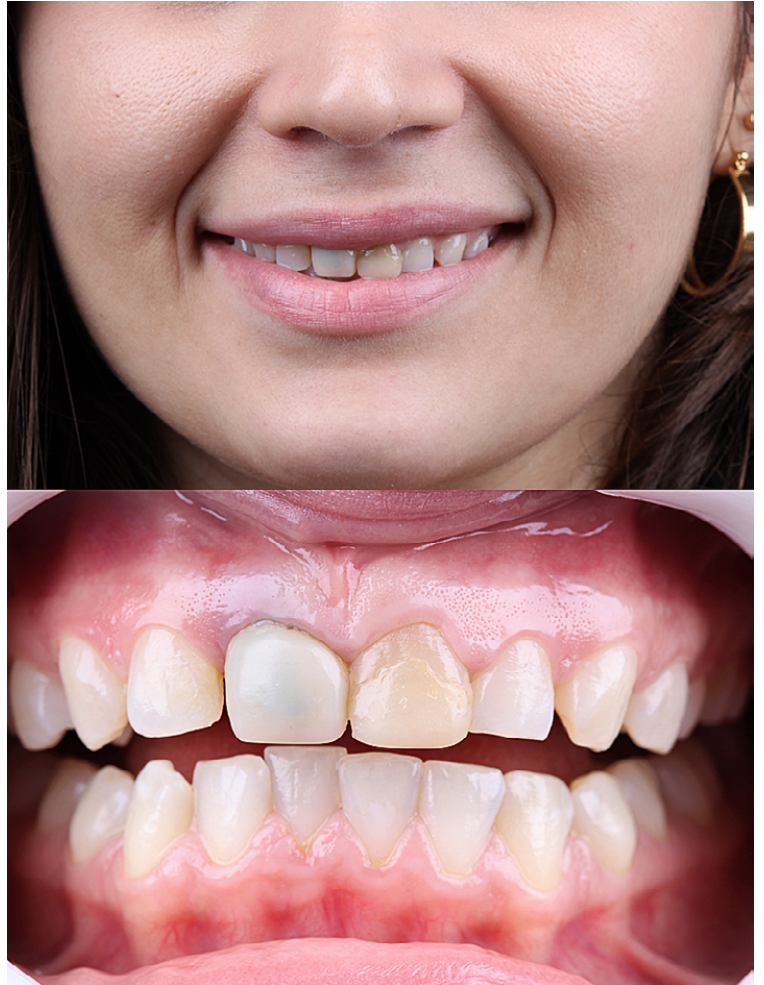

FIGURA 1 - Aspecto inicial do sorriso do paciente

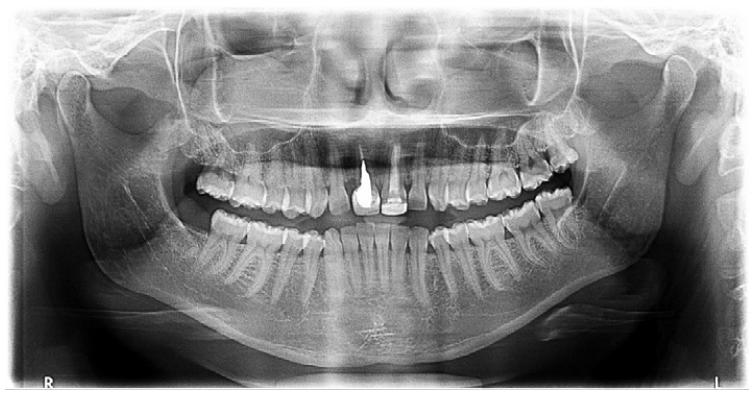

FIGURA 2 - Exame radiográfico

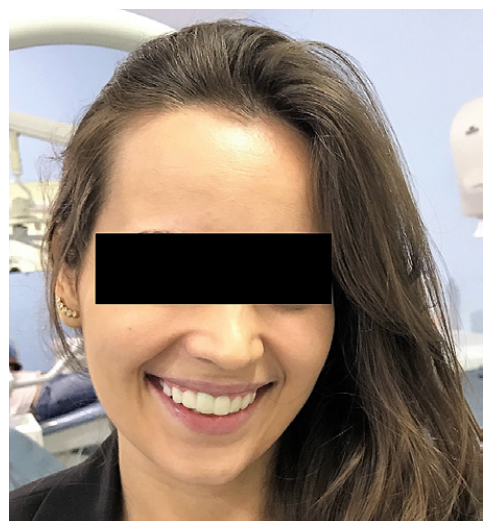

FIGURA 3 - Análise e ajuste do mock-up laterais, caninos e $1^{0}$ pré-molar. A paciente assinou o documento concordando com plano de tratamento então foi iniciado o tratamento.

A primeira etapa do tratamento foi a realização de moldagem com alginato (Hydrogum 5, Zhermack, Badia Polesine, RO, Itália) para obtenção de enceramento diagnóstico. $\mathrm{O}$ enceramento diagnóstico serviu como base para a confecção de três matrizes em silicone de condensação laboratorial ou silicone de adição, sendo elas a muralha de referências incisais e palatinas, a muralha de referência de desgastes vestibulares e a muralha do ensaio restaurador (mock-up).

A muralha de mock-up foi confeccionada utilizando-se silicone de adição (Express XT, 3M ESPE, St. Paul, Mn, EUA), em sua consistência densa, levado às áreas de interesse do modelo, sem a utilização de uma moldeira, sendo o material acomodado e esculpido de forma a cobrir todas as estruturas dentárias e os tecidos de suporte dos dentes envolvidos no planejamento e mais um dente para a distal de cada lado, de forma a se obter pontos de garantia de posição que mantenham a muralha em posição, quando esta for levada à boca. A matriz de silicone foi personalizada com lâmina de bisturi para recontorno 
cervical que proporcionou um mock-up preciso e sem excessos. Para o mock-up a matriz de silicone foi preenchida com resina bisacrílica (Protemp 4, 3M ESPE, St. Paul, Mn, EUA) e levada em posição. Observou-se que a customização do recontorno cervical facilitou a remoção dos excessos do material provisório. Após a presa da resina bisacrílica removeu a matriz personalizada e logo em seguida foi removida a camada superficial da resina com algodão embebido em álcool. O mock-up foi finalizado após remoção total dos excessos com lâmina de bisturi. A estética, simetria e contatos oclusais foram analisados (Figura 3).

A coroa e a restauração insatisfatórias foram removidas respectivamente com broca transmetal (\#1557T, Angelus Prima Dental, Londrina, PR, Brasil) e pontas diamantadas (\#3122 e \#2135, Kg Sorensen, Cotia, SP, Brasil). Foram confeccionados pinos de fibra anatômicos, devido ao amplo canal radicular. Realizou-se gengivoplastia com a técnica flapless para harmonizar o contorno gengival e foram confeccionados provisórios para os incisivos centrais.

Os preparos foram confeccionados a partir das muralhas de referências incisais e palatinas e da muralha de referência de desgastes vestibulares. Estas muralhas foram levadas em posição na boca e permitiram a visualização das diferenças entre as áreas que receberam acréscimo de cera, no enceramento diagnóstico, e os espaços vazios em boca, permitiram assim verificar se a espessura e as dimensões do preparo estavam corretos (Figura 4).

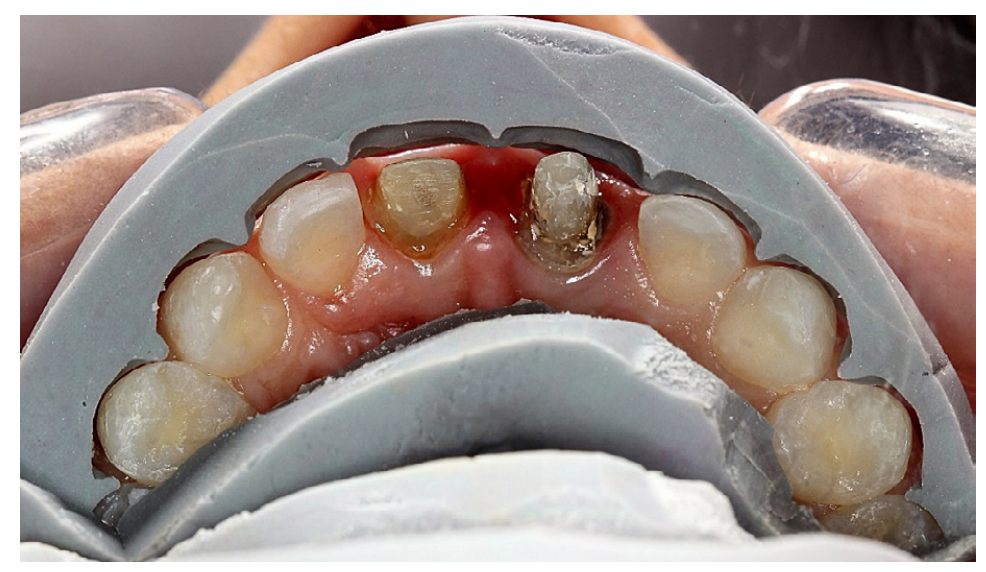


Um preparo conservador para coroa metal-free foi realizado nos incisivos centrais superiores; e para laminados cerâmicos nos incisivos laterais, caninos e pré-molares utilizando uma broca diamantada de granulação fina (\#1012 e \#2135F, KG Sorensen, Cotia, $\mathrm{SP}$, Brasil), seguido de acabamento do preparo com brocas multilaminadas (\#118L, Angelus Prima Dental, Londrina, PR, Brasil) e discos abrasivos flexíveis (Sof-lex, 3M ESPE, St. Paul, Mn, EUA).

O afastamento gengival foi obtido utilizando fio retrator (Ultrapak \#000, UltradentSouth, South Jordan, UT, EUA) (Figura 5). A cor final pretendida da cerâmica (BL3) foi selecionada com escala de cor junto à paciente (Ivoclar A-D, Ivoclar Vivadent, Schann Liechtenstein) (Figura 6). Os fios de afastamento foram removidos. A moldagem foi realizada com silicone de adição, na técnica de moldagem em passo único. O silicone pesado foi inserido na moldeira e em seguida o fluido foi aplicado primeiro sobre os dentes e depois na moldeira, e esta foi inserida na cavidade oral. Após 5 minutos, a moldeira foi retirada e verificada.

Foi realizado o registro interoclusal com silicone para registro oclusal (Scan Light, Yller, Pelotas, RS, Brasil) (Figura 7). No laboratório foi realizado o escaneamento do modelo de gesso para confecção do modelo digital, em seguida foi feito o planejamento digital das cerâmicas (Figura 8) e posterior fresagem

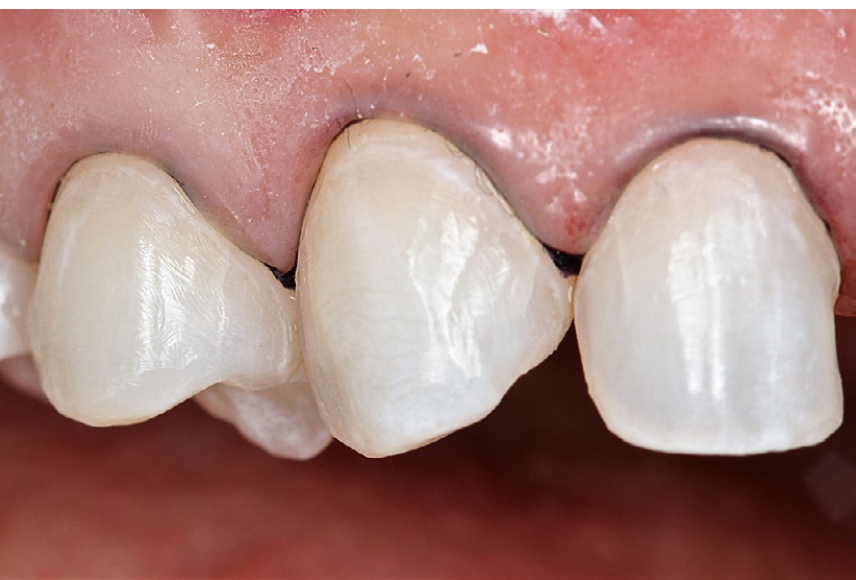

FIGURA 5 - Preparo minimamente invasivo para laminados cerâmicos

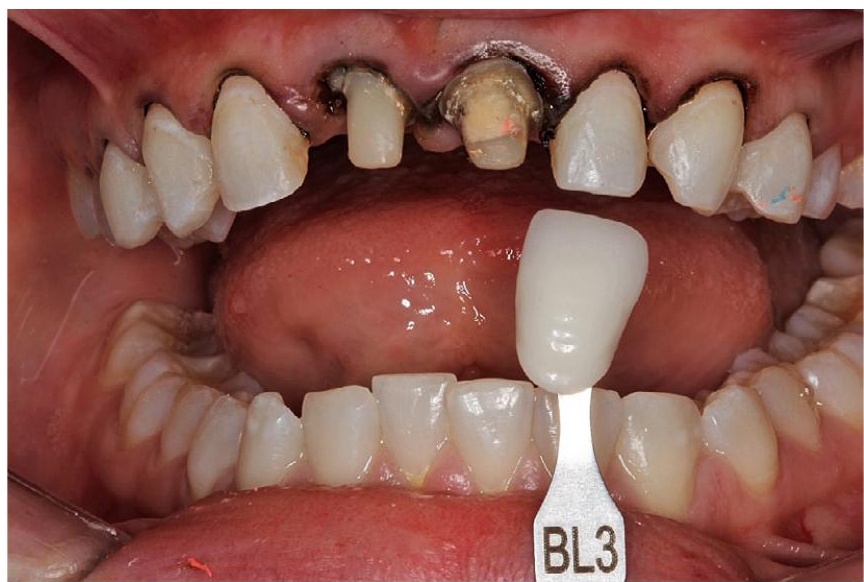

FIGURA 6 · Seleção de cor da cerâmica 
das peças. A cerâmica vítrea de dissilicato de lítio foi usada na confecção das peças (IPS e.max Press, Ivoclar Vivadent, Schann Liechtenstein) (Figura 9).

A adaptação proximal e cervical, relação periodontal e simetrias foram verificadas durante a prova seca. Uma cor de cimento resinoso de baixo valor (Opaque White) foi selecionada e confirmada usando pasta de teste (Allcem Veneer APS Try-In, FGM, Joinville, SC, Brasil). As superfícies internas das peças cerâmicas foram condicionadas com ácido fluorídrico a $10 \%$ por 20 segundos (Condac

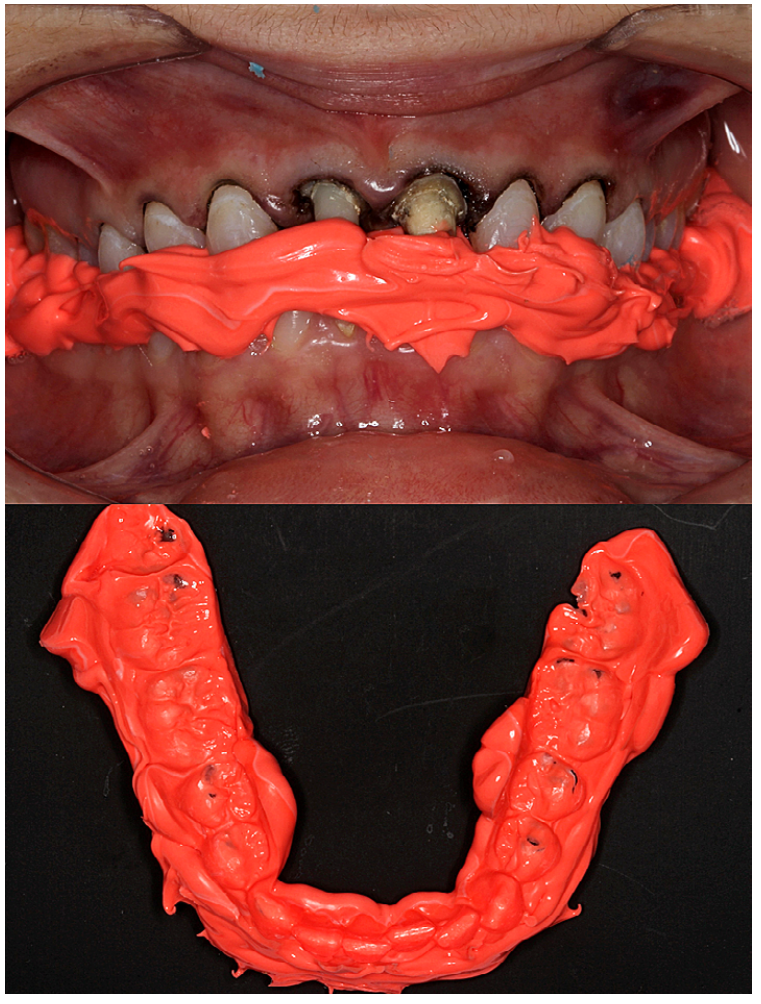

FIGURA 7 · Registro interoclusal

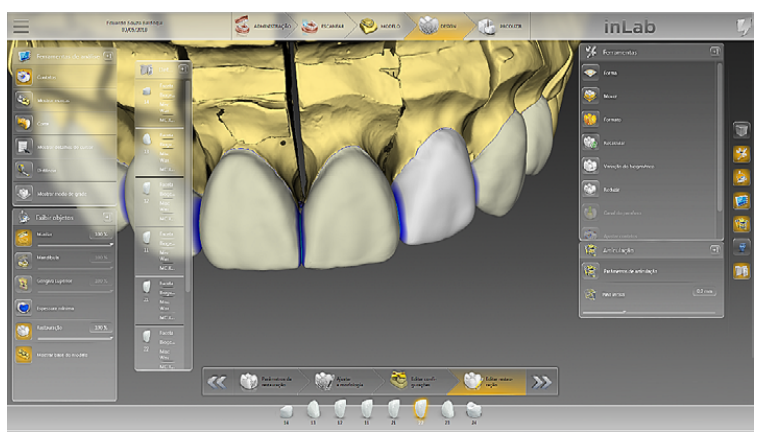

FIGURA 8 · Planejamento digital das cerâmicas

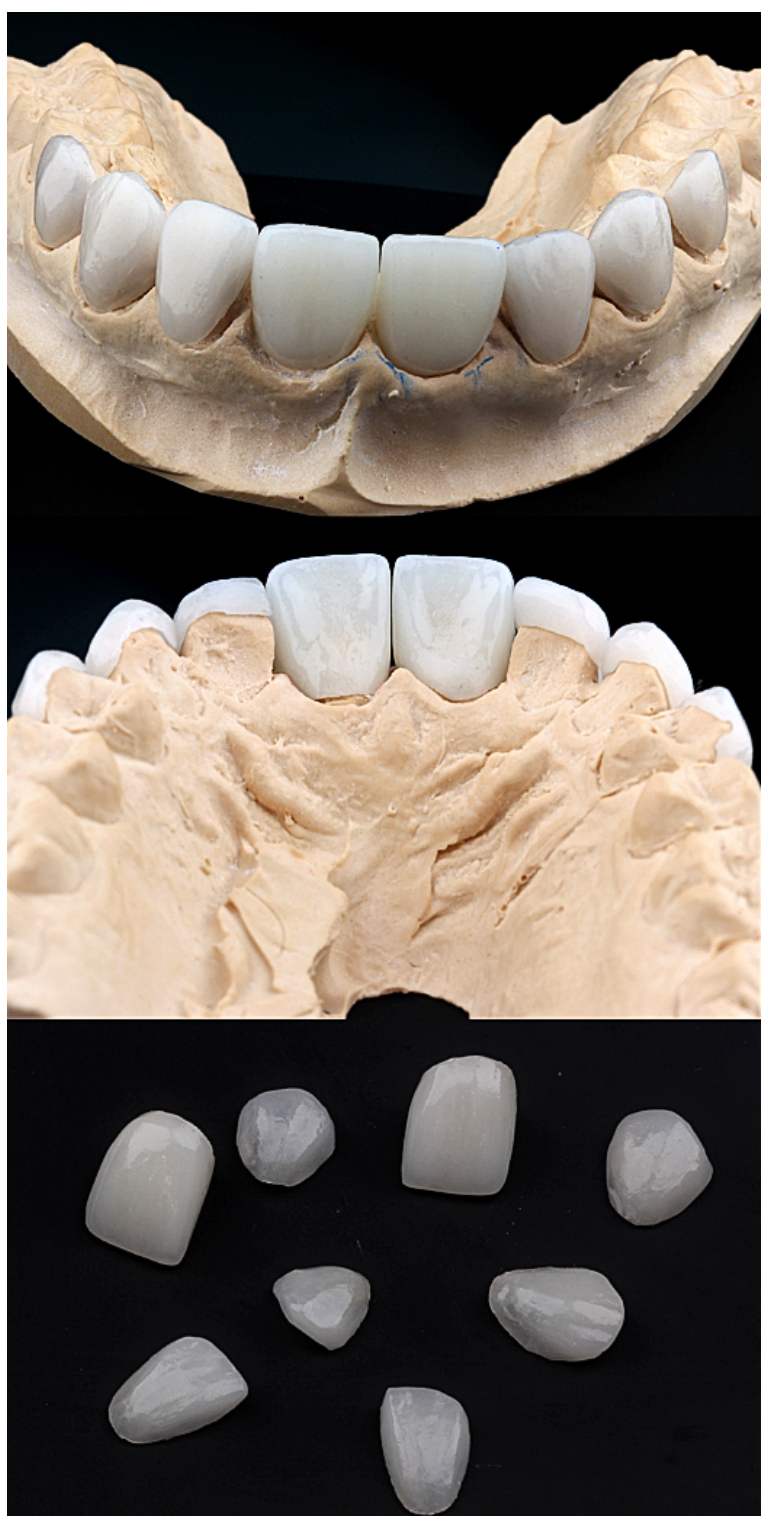

FIGURA 9 - Coroas e laminados cerâmicos de dissilicato de lítio 
Porcelana, FGM, Joinville, SC, Brasil) e foram lavadas com água. Foi feito um esfregaço com ácido fosfórico a 37\% (Condac, FGM, Joinville, SC, Brasil) por 30 segundos para remover detritos residuais e foram lavadas novamente. As restaurações foram silanizadas com um agente de acoplamento silano (Prosil, FGM, Joinville, SC, Brasil) por 60 segundos e depois seco com leve jato de ar, para evaporação total dos solventes nele presentes.

Para o preparo da superfície dentária os dentes adjacentes foram protegidos (Isotape, TDV Dental, Pomerode, SC, Brasil). O substrato dental foi condicionado com ácido fosfórico a $37 \%$ (Condac, FGM, Joinville, SC, Brasil) por 30 segundos em esmalte e 15 segundas em dentina, após este tempo foram lavados com água e secados. Foi feita a aplicação do agente adesivo (Scotchbond, 3M ESPE, St. Paul, Mn, EUA), seguido de jato de ar para remoção de excessos e obtenção de uma película bastante fina de adesivo. Após a aplicação do adesivo, nos dentes que seriam coroas foi feita fotopolimerização por 20 segundos, com unidade fotopolimerizadora de $1200 \mathrm{~mW} / \mathrm{cm}^{2}$ de irradiância (Radii-Cal, SDI, Bayswater, Victoria, Austrália), e nos dentes em que seriam laminados cerâmicos não foi feita fotopolimerização para evitar a formação de uma película que impeça o assentamento passivo da cerâmica.

Foi utilizado nas coroas o cimento resinoso autoadesivo e de polimerização dupla na cor A2 (Relyx U200 3M ESPE, St. Paul, Mn, EUA) e nos laminados cerâmicos o cimento resinoso fotopolimerizável na cor Opaque White (Allcem Veneer APS, FGM, Joinville, SC, Brasil). O excesso de cimento foi removido com um microaplicador (KG brush, KG Sorensen, Cotia, SP, Brasil), e cada uma das superfícies foi fotopolimerizada durante 60 segundos (Figura 10). Foi removido os excessos de cimento e foi realizado o acabamento e polimento nas margens da cerâmica. Os contatos oclusais foram identificados e ajustados. Os movimentos de protrusão e lateralidade foram verificados. A aparência final é mostrada na Figura 11. 


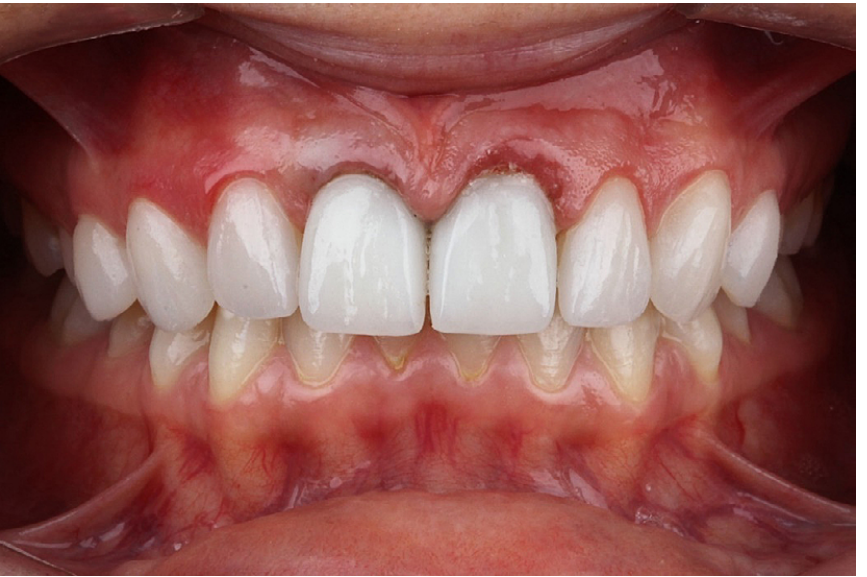

FIGURA $10 \cdot$ Peças cimentadas

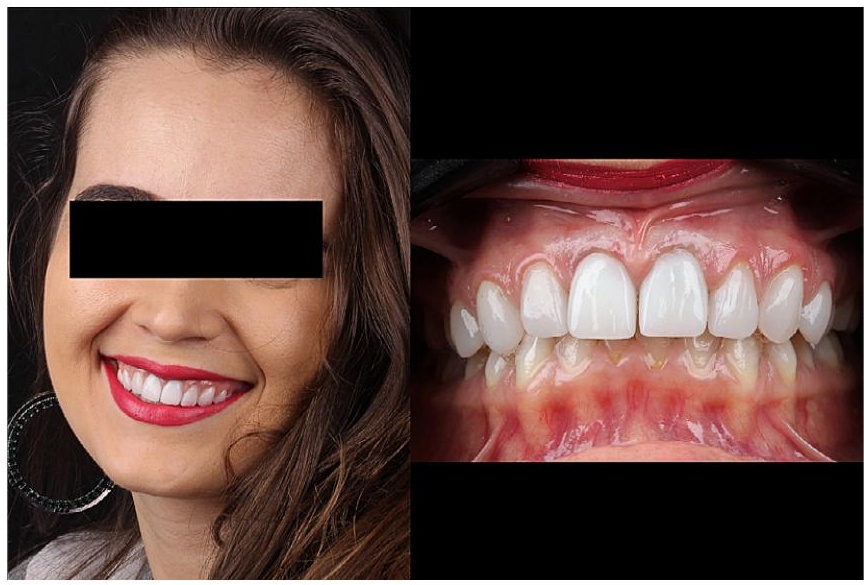

FIGURA 11 - Aspecto final do sorriso da paciente

\section{Discussão}

Os padrões de beleza atuais fizeram com que a paciente procurasse a reabilitação oral, devido à exigência da qualidade estética de um sorriso cada vez mais harmônico ${ }^{5,6}$. Atualmente, com ferramentas como um estudo fotográfico, modelos de estudo, enceramento e mock-up é possível um correto diagnóstico e previsibilidade do projeto estético, melhorando o planejamento do desgaste em esmalte nos ângulos, convexidades e retenções que impossibilitam o correto eixo de inserção e a restauração provisória ${ }^{5}$. A confecção do mock-up possibilita uma melhor visão e diálogo entre dentista, protético e paciente, para melhor escolha do material a ser utilizado, a forma e a cor dos laminados cerâmicos ${ }^{11,12}$.

No caso clínico relatado neste trabalho as coroas e laminados de dissilicato de lítio tinham como objetivo mimetizar a cor e formato dos dentes. A paciente já havia feito outros tratamentos odontológicos, entretanto se queixava de insatisfação com a estética. A partir da queixa estética juntamente com a avaliação do substrato dentário optou-se pela reabilitação com cerâmica, pois neste caso acreditou ser mais favorável do que a reabilitação com resina composta, em função da cerâmica ter a capacidade de reproduzir a aparência dos dentes naturais, apresentar comportamento biomecânico similar ao do esmalte e maior longevidade ${ }^{13,14}$. 
Com a evolução dos materiais odontológicos, as cerâmicas têm se tornado uma ótima opção para procedimentos restauradores estéticos indiretos, sendo uma alternativa superior à resina composta para modificação estética dos dentes ${ }^{15}$. A reabilitação da estética do sorriso com cerâmicas ultrafinas é indicada para correção de alterações morfológicas, embora devido à espessura, essas facetas têm aplicação limitada para mudança de cor em mais de dois tons acima da escala ${ }^{12}$.

A presença de coroas totais e laminados cerâmicos, com diferentes espessuras e translucidez, faz necessário usar a pasta de prova (try-in) antes da cimentação para simular a cor do cimento, e o protocolo de cimentação é crítico para a longevidade do tratamento ${ }^{16,17}$. É essencial o uso exclusivo de cimento totalmente fotoativado nos laminados cerâmicos, pelo fato de que os cimentos quimicamente ativados e duais apresentam em sua composição a amina terciária como ativador químico, que pode provocar alterações de cor com o passar do tempo, comprometendo o resultado estético, em função da baixa espessura do laminado ${ }^{18}$.

A vantagem principal da técnica indireta é o controle extra bucal da forma, caracterização, acabamento, polimento, devolução dos pontos ou faces de contato e adaptação da cerâmica ao término cervical ${ }^{19}$. As cerâmicas apresentam estabilidade de cor em longo prazo, alta resistência à fratura quando corretamente indicados e aderidos aos dentes, durabilidade, coeficiente de expansão térmica próxima da estrutura dental, baixa condutividade térmica, compatibilidade biológica e resistência à compressão ${ }^{2,20}$.

A tecnologia CAD/CAM apresenta vantagens como otimização do tempo, maior facilidade na transmissão de dados a outros profissionais e laboratórios, sustentabilidade, maior precisão no planejamento das restaurações definitivas, logo maior previsibilidade, pois permite que o paciente participe diretamente na elaboração das restaurações ${ }^{21-23}$. Entretanto há ainda as 
limitações no fator custo, que é relativamente alto, e é preciso habilidade do cirurgião-dentista e do laboratório na execuçao e planejamento de casos com essa tecnologia, que se torna a cada dia mais presente no dia a dia dos profissionais de saúde $e^{21-23}$.

As características da técnica indireta juntamente com a utilização de sistemas de CAD/CAM demonstram um alto potencial para uma adaptação marginal previsível de poucos micrômetros quando comparada com sistemas anteriores, além da manutenção da integridade do tecido periodontal subjacente e elevado grau de satisfação por parte dos pacientes ${ }^{8,19}$.

\section{Conclusão}

A estética não deve ficar restrita apenas à devolução da forma e função dos elementos dentários, mas também na capacidade de restabelecer um novo sorriso mais harmonioso e satisfatório, levando em consideração as expectativas do paciente. Sorriso que deve ser construído em conjunto entre dentista, paciente e técnico de prótese, tendo a preocupação de preservar os tecidos dentários e manter a saúde do tecido periodontal.

Pode-se concluir que é possível a recuperação da estética e da função em pacientes insatisfeitos com seu sorriso, através da reabilitação com cerâmicas odontológicas.

\section{Referências}

1 - Cotert HS, Dundar M, Ozturk B. The effect of various preparation designs on the survival of porcelain laminate veneers. J Adhes Dent. 2009; 11(5): 405-11.

2 - Hong N, Yang H, Li J, Wu S, Li Y. Effect of Preparation Designs on the Prognosis of Porcelain Laminate Veneers: A Systematic Review and Meta-Analysis. Oper Dent. 2017; 42(6): 197-213.

3 - Wolff D, Kraus T, Schach C, Pritsch M, Mente J, Staehle HJ, et al. Recontouring teeth and closing diastemas with direct composite buildups: a clinical evaluation of survival and quality parameters. J Dent. 2010; 38(12): 1001-9.

4 - Beier US, Dumfahrt H. Longevity of silicate ceramic restorations. Quintessence Int. 2014; 45(8): 637-44. 
5- Walter RD, Raigrodski AJ. Critical appraisal: clinical considerations for restoring mandibular incisors with porcelain laminate veneers. J Esthet Restor Dent. 2008; 20(4): 276-81.

6 - Guess PC, Stappert CF, Strub JR. Preliminary clinical results of a prospective study of IPS e.max Press- and Cerec ProCAD- partial coverage crowns. Schweiz Monatsschr Zahnmed. 2006; 116(5): 493-500.

7 - Kelly JR, Nishimura I, Campbell SD. Ceramics in dentistry: historical roots and current perspectives. J Prosthet Dent. 1996; 75(1): 18-32.

8 - Nejatidanesh F, Savabi G, Amjadi M, Abbasi M, Savabi O. Five year clinical outcomes and survival of chairside CAD/CAM ceramic laminate veneers - a retrospective study. J Prosthodont Res. 2018; 62(4): 462-7.

9- Fuster-Torres MA, Albalat-Estela S, Alcaniz-Raya M, PenarrochaDiago M. CAD / CAM dental systems in implant dentistry: update. Med Oral Patol Oral Cir Bucal. 2009; 14(3): 141-5.

10 - Calamia JR, Calamia CS. Porcelain laminate veneers: reasons for 25 years of success. Dent Clin North Am. 2007; 51(2): 399-417.

11 - Morley J. The role of cosmetic dentistry in restoring a youthful appearance. J Am Dent Assoc. 1999; 130(8): 1166-72.

12 - Soares PV, Spini PH, Carvalho VF, Souza PG, Gonzaga RC, Tolentino $\mathrm{AB}$, et al. Esthetic rehabilitation with laminated ceramic veneers reinforced by lithium disilicate. Quintessence Int. 2014; 45(2): 129-33.

13 - Miranda ME, Olivieri KA, Rigolin FJ, Basting RT. Ceramic fragments and metal-free full crowns: a conservative esthetic option for closing diastemas and rehabilitating smiles. Oper Dent. 2013; 38(6): 567-71.

14 - Wolfart S, Eschbach S, Scherrer S, Kern M. Clinical outcome of threeunit lithium-disilicate glass-ceramic fixed dental prostheses: up to 8 years results. Dent Mater. 2009; 25(9): 63-71.

15 - Andrade OS, Ferreira LA, Hirata R, Rodrigues FP, D’Alpino PH, Di Hipolito V. Esthetic and functional rehabilitation of crowded mandibular anterior teeth using ceramic veneers: a case report. Quintessence Int. 2012; 43(8): 661-70.

16 - Blatz MB, Sadan A, Kern M. Resin-ceramic bonding: a review of the literature. J Prosthet Dent. 2003; 89(3): 268-74.

17 - Turgut S, Bagis B. Colour stability of laminate veneers: an in vitro study. J Dent. 2011; 39(3): 57-64.

18 - Dozic A, Tsagkari M, Khashayar G, Aboushelib M. Color management of porcelain veneers: influence of dentin and resin cement colors. Quintessence Int. 2010; 41(7): 567-73.

19 - Bispo LB. Laminados cerâmicos na clínica integrada. Rev. Odontol. Univ. Cid. São Paulo. 2018; 30(1): 83-94. 
20 - Sa TCM, Figueiredo de Carvalho MF, Sa JCM, Magalhaes CS, Moreira AN, Yamauti M. Esthetic rehabilitation of anterior teeth with different thicknesses of porcelain laminate veneers: An 8-year follow-up clinical evaluation. Eur J Dent. 2018; 12(4): 590-3.

21 - Sancho-Puchades M, Fehmer V, Hammerle C, Sailer I. Advanced smile diagnostics using CAD/CAM mock-ups. Int J Esthet Dent. 2015; 10(3): 374-391.

22 - Tsirogiannis P, Reissmann DR, Heydecke G. Evaluation of the marginal fit of single-unit, complete-coverage ceramic restorations fabricated after digital and conventional impressions: a systematic review and meta-analysis. J Prosthet Dent. 2016; 116(3): 328-335.

23 - Ender A, Attin T, Mehl A. In vivo precision of conventional and digital methods of obtaining complete-arch dental impressions. J Prosthet Dent. 2016; 115(3): 313-320. 


\title{
Obtaining the aesthetics of the smile through ceramic laminates and free metal crowns: case report
}

\begin{abstract}
Objective: This case report aimed to improve the aesthetics of the anterior teeth, highlighting the stages in dental rehabilitation, using crowns and laminates of ceramic reinforced by lithium disilicate. Material and Method: After preliminary and diagnostic procedures such as the study model, waxup, and mock-up, the preparations were followed, followed by addition silicone molding, and the crowns and laminates were made and cemented with resin cement. Results: As a result of this, we realized that aesthetics should not only return the form and function of dental elements, but re-establish a new smile for the patient, with the concern of preserving the dental tissues and maintaining the health of the periodontal tissue. Conclusion: After the report of this clinical case, we realized that it is possible to reestablish the aesthetics and function in patients dissatisfied with their smile, through the rehabilitation with ceramics.
\end{abstract}

KEYWORDS: Esthetics, Dental; Ceramics; Dental veneers.

\section{Como citar este artigo}

Gomes RR, Almeida GM, Almeida KTRS, Almeida Júnior JC. Obtenção da estética do sorriso através de laminados cerâmicos e coroas metal free: relato de caso. Rev Odontol Bras Central 2021; 30(89): 232-245. DOI: 10.36065/robrac.v30i89.1345 